\title{
O retalho pleural na perfuração do esôfago torácico
}

\section{The pleural wrap in the thoracic esophageal perforation}

\author{
Aderivaldo Coelho de Andrade, TCBC-PI'; Zenon Rocha Filho, TCBC-PI²; Valrian Campos Feitosa3; jocerlano Santos de Sousa3; \\ LUIZ JOAQUIM FONSECA MARINHO FILHO ${ }^{3}$
}

\section{INTRODUÇÃO}

\begin{abstract}
$A^{s}$ perfurações esofagianas torácicas quando submetidas à sutura primária freqüentemente complicam com fístulas para o mediastino o que faz aumentar a mortalidade, sendo a mediastinite e o empiema pleural complicações temíveis. Portanto, torna-se imperativo o reforço da sutura primária com tecido autógeno vascularizado que tem demonstrado redução da incidência das fístulas esôfagopleurais e da mortalidade. Para este fim podem ser utilizados retalhos de pleura parietal, diafragma, fundo gástrico e músculos (intercostal, rombóide, peitoral, esternocleidomastóideo).

No caso em que se segue, relata-se uma perfuração esofagiana extensa em que foi realizado um reforço da esofagorrafia utilizando-se retalho de pleura.
\end{abstract}

\section{RELATO DE CASO}

R.A.A, 37 anos, masculino, foi admitido no Pronto Socorro do Hospital Getúlio Vargas, em Teresina - Pl, doze horas após ser atropelado por um caminhão, apresentando dor torácica intensa, dispnéia, dor abdominal e de quadril. Informava que após o atropelamento apresentou vômitos intensos. Ao exame físico apresentava creptação em tórax, retração da expansibilidade do hemitórax esquerdo e ausência de murmúrio vesicular à esquerda. Abdome doloroso difusamente e dor intensa à palpação do quadril. Estudo radiográfico simples revelou hidropneumotórax ocupando todo o hemitórax esquerdo, bem como grande afastamento da sínfise púbica.

Após medidas ressuscitatórias, o paciente foi submetido a laparotomia exploradora, sem lesões viscerais, e drenagem torácica à esquerda com exteriorização de restos alimentares pelo dreno. Endoscopia digestiva alta realizada no centro cirúrgico demonstrou lesão longitudinal extensa no esôfago torácico inferior, iniciando a $30 \mathrm{~cm}$ da arcada dentária superior e prolongando-se por $7 \mathrm{~cm}$ ao longo da parede lateral esquerda. Foi realizada toracotomia esquerda, confirmando-se a lesão (Figura 1). Foram identificadas as bordas da lesão e dos ângulos, com maior dificuldade na exposição da mucosa no ângulo superior.
Procedeu-se a esofagorrafia em dois planos com fio de poliglactina 3.0, e confeccionado retalho de pleura parietal como reforço. Foi realizada drenagem torácica à direita e à esquerda. Durante a operação colocou-se sonda nasogástrica e feita ampla lavagem do estômago com remoção de grande quantidade de comida ainda não digerida que saía ou pela sonda ou pelo lesão esofágica. A sonda permaneceu por 48 horas e foi removida. Realizou-se antibioticoterapia de amplo espectro e utilizou-se omeprazol $(80 \mathrm{mg} / \mathrm{dia})$ endovenoso. No $3^{\circ}$ dia foi iniciada nutrição parenteral central. No $7^{\circ}$ dia esofagograma com contraste iodado mostrou fístula esofágica em fundo cego, sem extravasamento para a cavidade pleural, além disso, quando realizado o último filme sem administrar contraste, já não se notava o conteúdo extravasado, pois o mesmo já tinha retornado ao esôfago. (Figura 2).

O dreno torácico funcionou nos primeiros dias com saída de secreção serosa, sendo que após o $7^{\circ}$ dia não drenava mais qualquer secreção. Este fato, associado a novo esofagograma no $14^{\circ} \mathrm{dia}$, mostrando uma fístula em fundo cego sem extravasamento para a cavidade pleural, permitiu

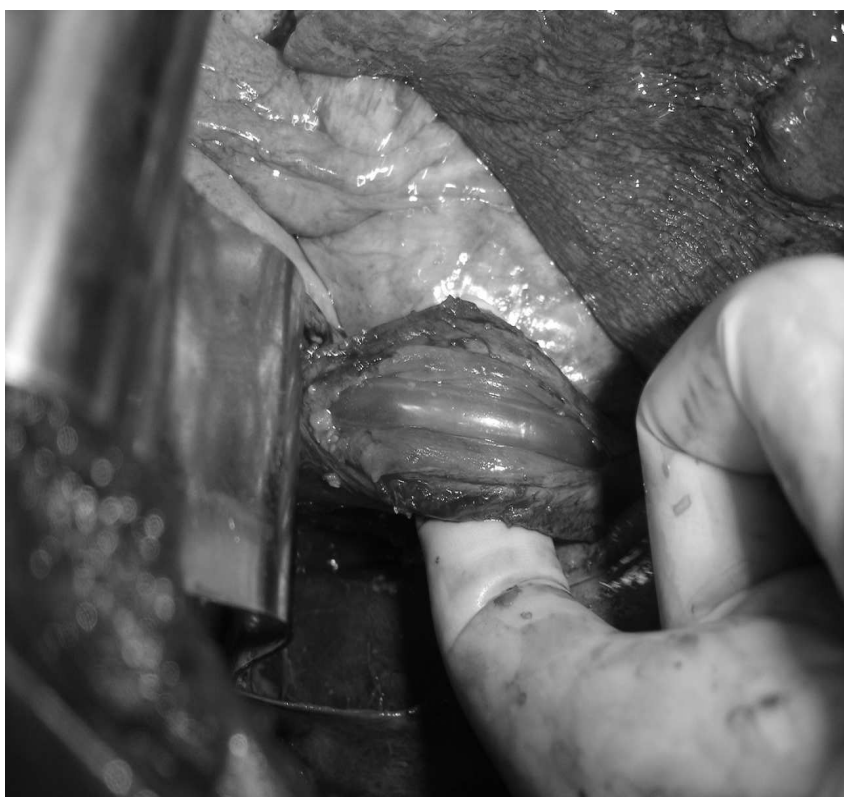

Figura 1 - Lesão esofágica evidenciada após toracotomia esquerda.

Trabalho realizado na Clínica Cirúrgica do Hospital Getúlio Vargas (HGV) - Universidade Federal do Piauí- Teresina - PI - BR

1. Cirurgião-Assistente da Clínica Cirúrgica do Hospital Getúlio Vargas, Teresina - PI-BR; 2. Professor Titular da Clínica Cirúrgica do Hospital Getúlio Vargas, Teresina- PI-BR; 3. Cirurgião Geral Formado na Clínica Cirúrgica do Hospital Getúlio Vargas, Tersina- PI-BR. 
a remoção do dreno com segurança. Dessa forma, entre o $14^{\circ}$ e o $27^{\circ}$ dias o paciente ficou sem drenagem torácica e não houve qualquer acúmulo de secreção, com sintomatologia, em seu mediastino ou hemitórax esquerdo. Novo esofagograma foi realizado, mostrando esôfago normal. O paciente foi realimentado por via oral e teve alta no $30^{\circ}$ dia.

\section{DISCUSSÃO}

As perfurações esofagianas torácicas continuam sendo um desafio para o cirurgião, especialmente quando o diagnóstico é retardado ${ }^{1-5}$. Ampla variedade de sintomas foi descrita em diversos trabalhos. A dor é o sintoma mais comum, ocorrendo em $70 \%$ a $90 \%$ dos pacientes; febre ocorre em $50 \%$ a $70 \%$ já no início do quadro clínico, creptação na parede torácica ou cervical é sinal de doença avançada, notado em menos da metade dos pacientes. Após 24 horas de perfuração ou quando há perda de substância o reparo primário já não é tão eficaz, porque aumenta o risco de deiscências da sutura e fístulas, levando a quadros graves de empiema pleural ou mediastinite, com alta taxa de mortalidade ${ }^{3}$. Nesses casos deve ser confeccionado um reforço da sutura através de retalho vascularizado, com o objetivo de reduzir a incidência de fístulas, ou pelo menos reduzir a intensidade do vazamento com a contenção do conteúdo extravasado pelo retalho fixado ao esôfago 4 . É fundamental a visualização da mucosa, devendo-se fazer desbridamento dos tecidos desvitalizados após abertura da camada muscular, efetuar sutura da mucosa com pontos separados e a sutura da muscular, se não for possível suturar as duas camadas separadamente fazer em plano único muscular-mucosa. A seguir realiza-se a confecção do retalho ancorando à sutura 5 .

A freqüente falha no fechamento retardado da perfuração esofágica levou a uma série de tentativas de reforçar a linha de sutura com tecidos autógenos. Thal em 1964 sugeriu o fundo gástrico para perfurações do esôfago distal. Em 1975, Grillo descreveu o uso de envoltório pleural autógeno em quatro pacientes ${ }^{1}$. Recentemente, retalhos musculares têm sido usados com freqüência crescente ${ }^{4,5}$.

Para esôfago cervical, o melhor reforço é provavelmente o retalho de peitoral maior, principalmente pela sua mobilidade e vascularização. O esternocleidomastóideo é também proposto, mas a freqüência de necrose é considerável. Em perfurações torácicas, vários tecidos podem ser facilmente mobilizados e utilizados para recobrir a li-

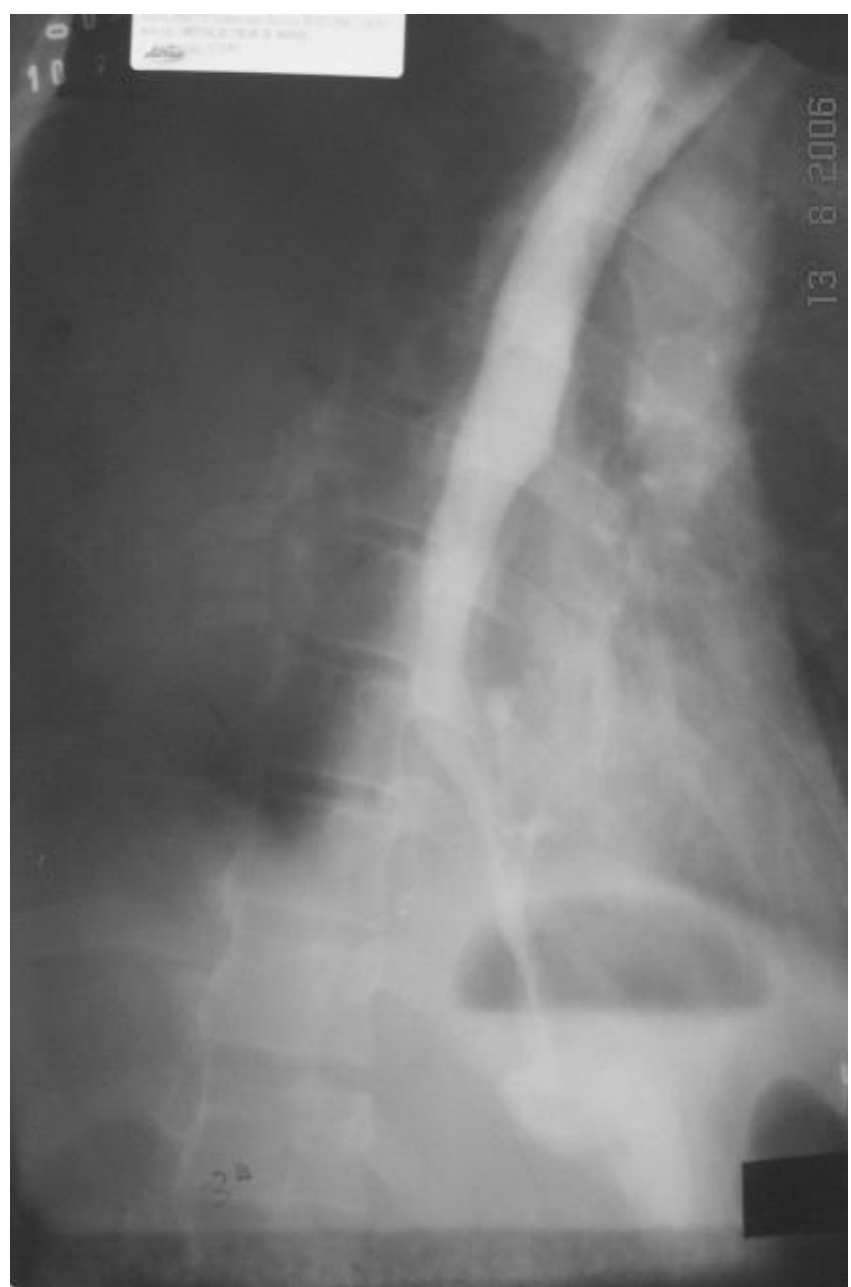

Figura 2 - Fístula esofágica em fundo cego mostrado por esofagograma.

nha de sutura esofágica. O mais comum é o retalho pleural preconizado por Grillo porque é de fácil utilização e de utilidade notória especialmente após diagnóstico tardio quando a pleura tornou-se espessada pelo processo inflamatório. No abdome o reforço da sutura com fundo do estômago a Thal é recurso bastante utilizado.

O caso descrito representa um trauma esofagiano extenso em que foi realizada esofagorrafia em dois planos, com reforço da sutura utilizando-se um retalho de pleura parietal, onde, apesar do aparecimento de pequeno vazamento, ele foi determinante para conter a fístula que se mostrou em fundo cego obliterando-se, em seguida, o seu trajeto, sem maiores complicações para o paciente.

\section{A B S S T R A C T}

The thoracic esophageal perforations frequently complicate with fistula when submitted to primary suture. The use of autogenous tissues, like pleura, to reinforce the primary suture has proved to be useful in reduce the incidence of fistulas or at least the severity of the leaks in case they occur. The mortality has reduced too, consequently. A case of an extensive esophageal perforation is presented, where the use of pleural wrap to reinforce the esophagorrafy was very important to contain the leak and to permit a good evolution of the patient.

Key words: Esophageal perforation. Pleural. Surgical flap. 


\section{REFERENCIAS}

1. Grillo HC, Wilkins EW Jr. Esophageal repair following late diagnosis of intrathoracic perforation. Ann Thorac Surg. 1975; 20(4):38799.

2. Whyte RI, lannettonl MD, Orringer MB. Intrathoracic esophagea perforation. The merit of primary repair. J.Thorac Cardiovasc Surg. 1995; 109(1):140-4; discussion 144-6.

3. Gouge TH, Depan HJ, Spencer FC. Experience with the Grillo pleural wrap procedure in 18 patients with perforation of the thoracic esophagus. Ann Surg. 1989; 209(5):612-7; discussion 617- 9.

4. Berger RL, Donato AT. Treatment of esophageal disruption by intubation. A new method of management. Ann Thorac Surg. 1972; 13(1):27-35.

5. Rosiere A, Mulier S, Khoury A, Michel LA. Management of esophageal perforation after delayed diagnosis: the merit of tissue flap reinforcement. Acta Chir Belg. 2003;103(5):497-501.
Recebido em 20/06/2006

Aceito para publicação em 22/08/2006

Conflito de interesse: nenhum

Fonte de financiamento: nenhuma

\section{Como citar esse artigo:}

Andrade AC, Rocha Filho Z, Feitosa VC, Sousa JS, Marinho Filho LJF. O retalho pleural na perfuração do esôfago torácico. Rev Col Bras Cir. [periódico na Internet] 2010; 37(4). Disponível em URL: http:// www.scielo.br/rcbc

Endereço para correspondência:

Aderivaldo Coelho de Andrade

E-mail: domderi@hotmail.com 